\title{
INCREASING TREND TOWARDS PASSIVE RECREATION IN THE METROPOLITAN
}

\author{
Muhammad Asim* \\ Rumana Khan Shirwani** \\ Saima Gulzar***
}

\begin{abstract}
Man is the basic entity of this universe, from the origin till now struggling for betterment in life with well organized mechanism pursing all the deeds for comfort and easiness. Man has made a lot of progress and advancement for pursuing daily routine work with the advancement of science and technology. Along with these advancements a number of subjects have evolved for serving human beings, which specifically work for the comfort of their social living and to aid physically and mentally, within an environment; like sociology, psychology environment and above all town planning. This study is conducted to highlight the changing trends of recreation from active to passive. The priorities of people engaging in different types of recreation have changed. People today prefer to go shopping, picnicking, watching movies and indoor sports instead of engaging in physical activities and sports like cricket, football, basketball, badminton, volleyball. The fact for this shift in trends are technological advancements in the field of communication, poor planning concepts, security threats and changed concepts of parenting focused on bounding children at home. Such shifts are physically deteriorating our younger generation leading them to slackness and laziness. Thus, planning objective of healthy society cannot be achieved and at present there is a need to conduct research on this issue and highlight the factors that are responsible for this change. This research visualizes the crucial aspects and puts forward policy recommendation for planners by using quantitative research approach based on qualitative survey.
\end{abstract}

Keywords: Active recreation, passive recreation, technological advancement

\section{INTRODUCTION}

Technological advancement is changing the trend and behavior of people around the globe. Technology is creating easement for people day by day, which leads to slackness and laziness in human nature (Hui-fen et al, 2012). Where technology creates easiness for society, it also brings stress in life as people are moving away from nature and the only way out is more engagement with active recreational activities (Sutton, 2008).

Few researches point out that too much artificial setting and time spent in purely human environments (commuting, enclosed space and indoor recreation etc) may cause fatigue and a loss of energy and health (Katcher and Beck, 1987) while other researchers conclude that natural settings e.g. landscape, birds and animals seem to engage attention and help in relaxing people (Kuo and Sullivan, 2001).

Recreation is an important activity for human beings. No one can deny its importance as it helps relax and keep human beings mentally and physically fit. On the basis of nature of activities, recreation has been divided into two types; active recreation and passive recreation. Active recreation involves both cognitive and physical development, while passive recreation involves no physical development. It has been seen that active recreation is declining with the passage of time, while there is a shift towards passive recreation due to a number of reasons (Friedmann, 2007).

The setting of urban spaces provide opportunities for active recreation and promote healthy life for citizens (Williams, 2000; Maller et al, 2002). Planning is not the only component responsible for the increase in passive recreation but there are other social issues also. Like, security is a big issue in a developing country like Pakistan. According to the interviews conducted for this research people are afraid of kidnapping and snatching. Media around the globe is showing the scariest picture of the world, which fears people. Nobody wants to send their children to a playground, where the child might get hurt, killed or kidnapped due to poor security. Further, it is also the view of people that during active games they can't get access to quick medication in case of injury due to lack of medical facilities as there are no sports clubs existing at the neighborhood scale.

* Dr. Muhammad Asim, Assistant Professor, Department of City and Regional Planning, University of Engineering and Technology, Lahore ** Rumana Khan Shirwani, Assistant Professor, School ofArchitecture and Planning, University of Management and Technology, Lahore *** Dr. Saima Gulzar, Associate Professor, School ofArchitecture and Planning, University of Management and Technology, Lahore 
It is one of the requirements of designing urban spaces to make better places for people and these spaces should be designed for all potential users alike without gender, class or age biases (Douglas, 2009). If places are not utilized due to lack of security then that is also lack of adequate planning policy implementation (Carmona, et.al., 2010).

One of the major causes for passive recreation is the use of internet and access to social media. Time is getting short for active recreation in this modern era. Priorities of people have changed around the globe (Saelens et al, 2003; Dong and Chick, 2012). Technological advancement has shifted the priorities, computers and mobiles especially social networks; like facebook, twitter, sms, call packages and community forums have completely trapped the human mind. People prefer to enjoy such type of passive recreation rather than having active recreation like sports, cricket, badminton, basketball etc. Moreover, work and academic stress push people towards passive recreation (McLean and Hurd, 2011). This leaves them with no time for any active recreation because they are exhausted due to academic work. Further, increase in competition in society engages people in long working hours at offices and they are left with no time for active recreation. Tired people with no time can engage in only passive recreation. Passive recreation does not need specific times e.g. a person can watch a movie at night but cannot go for sports at night time.

In this paper the reasons for increase in trends of passive recreation are studied. It is proved through research that increasing trends in passive recreation are deteriorating public health and comfort (Haughey, 2005; Frumkin et al, 2004).

\section{MATERIALS AND METHODS}

This research falls under comparative, explanatory and descriptive type (Howe, 2007; Brymann, 2008; Zhang, 2010). Therefore, it is necessary to have such techniques which give a detailed comparison both in numeric and descriptive form. For this purpose primary data collection techniques have been utilized for a thorough and detailed research. To arrive at rational results it was necessary to collect each bit of information regarding the research work, but it was not possible to cover whole case study area due to limited resources. Therefore, the sample size of thirty was taken as a thumb rule as qualitative research of different income groups was conducted (total sample size was 90).

The sample size was decided carefully to arrive at rational results. A sample size which presented the characteristics
Table 1: Summary of Sampling

\begin{tabular}{|llll|}
\hline Income Classes & $\begin{array}{l}\text { Selected Locality } \\
\text { in Lahore }\end{array}$ & $\begin{array}{l}\text { Sample } \\
\text { Size }\end{array}$ & $\begin{array}{l}\text { Net Household } \\
\text { Income }\end{array}$ \\
Middle Income & $\begin{array}{l}\text { Wireless colony, } \\
\text { GT Road }\end{array}$ & 30 & Below $2 \$$ \\
Shah Bagh & 30 & $\begin{array}{l}\text { Above } 2 \$ \text { and } \\
\text { below } 10 \$\end{array}$ \\
High Income & Model Town & 30 & Above $10 \$$ \\
\hline
\end{tabular}

of whole case study area was decided upon. For this purpose, three areas were selected on the basis of income division. The available facilities for active recreation for different income groups and its trends were documented. Parameters were defined for the selection of income classes. These parameters were: household net income with an average household size of six. The income for high income class was considered above $10 \$$ per day, for middle income class was between above $2 \$$ and below $10 \$$ per day, and that for low income class was below $2 \$$ (PIDE, 2011). Table-1 shows the summary of sample size and selected areas in Metropolitan area of Lahore.

The purpose behind the selection of different economic classes was to probate the trend in different income classes within the city. This selection helped in asserting the recreational development corresponding to different income level towards active or passive recreation, and to explore the factors behind peoples attitude towards recreational activities and the impact of technology.

\section{DISCUSSION ON FINDINGS}

The city planning should include provisions/ considerations for the physical and cognitive fitness facilities which is only achievable when people are provided with equal opportunity of both active and passive recreation (Frank et al, 2003; Saelens et.al, 2003a). It has been found that people are more focused towards cognitive/ passive recreation in the present technological era instead of active recreational activities. One of the main observed factors is the absence of active recreational planning standards in the public sector development agencies.

\section{Playground in Vicinity}

Provision of playground in each locality is the basic right of inhabitants, but unfortunately most of our built up areas lack this provision which results in change of interest of the people from active to passive recreation (Table-2). Most of 
Table 2: Playground status in vicinity

\begin{tabular}{|llll|}
\hline Income Groups & Yes & No & Total \\
Low Income & $36.7 \%$ & $63.3 \%$ & $100 \%$ \\
Middle Income & $20 \%$ & $80 \%$ & $100 \%$ \\
High Income & $46.70 \%$ & $53.30 \%$ & $100 \%$ \\
\hline
\end{tabular}

the respondents did not have playground in the vicinity. Only $20 \%$ of middle and $30 \%$ of low income groups have playgrounds. The survey results show insufficient provision of playgrounds in the middle and low income areas. This is a push factor towards passive recreation, as people are unable to develop their interests towards active recreation and are ultimately forced towards watching television and browsing the internet. Further, low and middle income areas have not developed according to the recent planning standards. This is also one of the reasons for absence of playground in the vicinity. High income areas have developed some planning standards and play grounds exist at convenient distances, but still people believe that they are not planned within walking distance.

\section{Occupation Base Analysis}

Recreation has a great impact on the efficiency and output rate of any job, as it plays an important role to relax the worker mentally and physically. In real terms the actual purpose behind conducting this research was the health and convenience, which can only be achieved if people have balance in their daily routine activities. It has been seen that students in high and middle income groups visit parks and playgrounds more than students in low income groups (Figure 1) as playgrounds are within their easy access. While having a glance on all the professions it seems people belonging to high income groups frequent the play grounds more than people of middle and low income groups by about $25 \%$. People employed in offices use the parks more than people employed in other areas of work by about $23 \%$. This is an interesting finding and the reason behind this is the awareness of pursuing a healthy life.

\section{Impact of Technology}

The main stream of this research is to cover the impact of technology and the choice of recreation. No doubt one of the most affecting reasons behind increased trend towards passive recreation is the impact of technology. In order to assess the impact of technology on people, it is necessary to review factors like available recreational facilities, free time available and the attitude towards recreation.

\section{Availability of T.V/Cable and Internet Facility}

When reviewing the impact of technology the affects of cable television and internet usage are assessed first. The advancement in communication has left almost no house without these facilities in any low, middle and high income groups (Figure 2). There are very few houses in low income areas that have no access to such facilities. It is $20 \%$ and $67 \%$ of the low income class that has no T.V/cable and

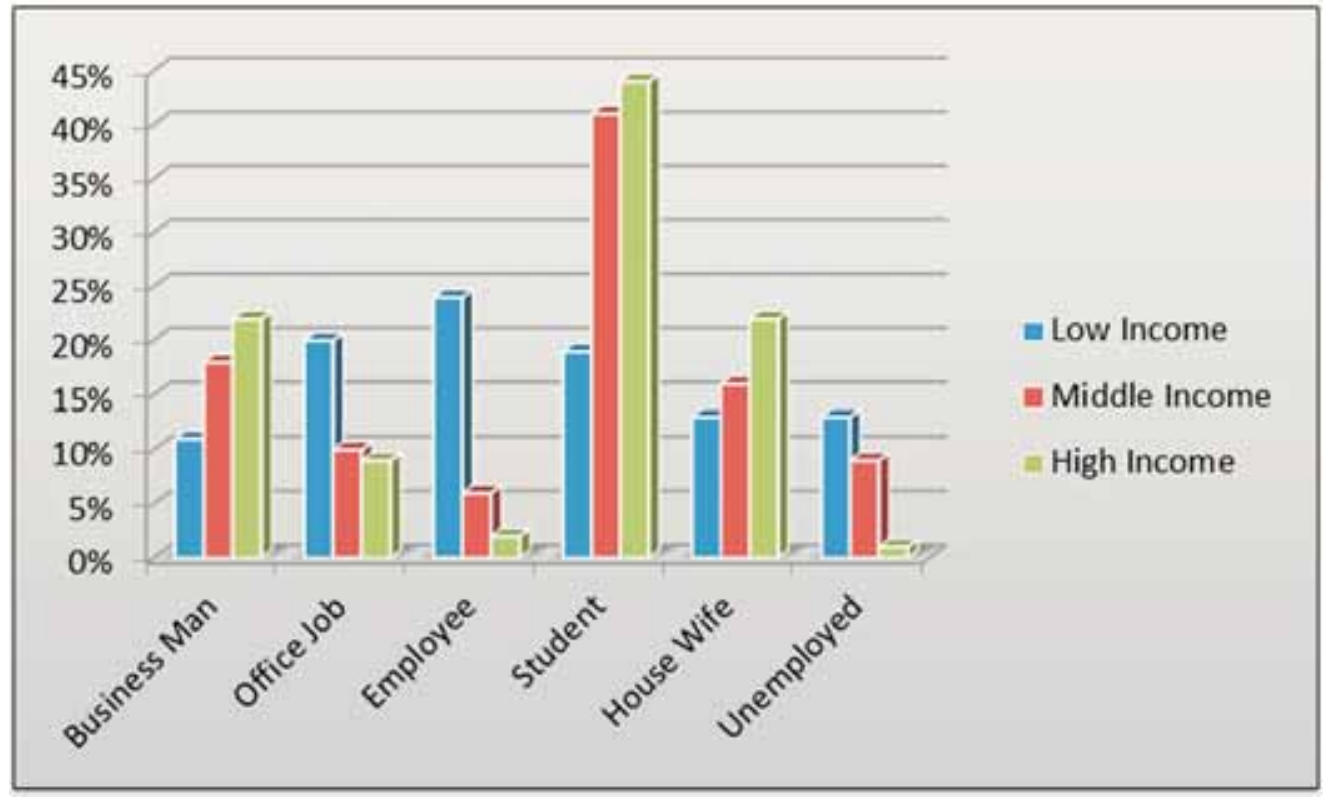

Figure 1: Occupation base analyses 


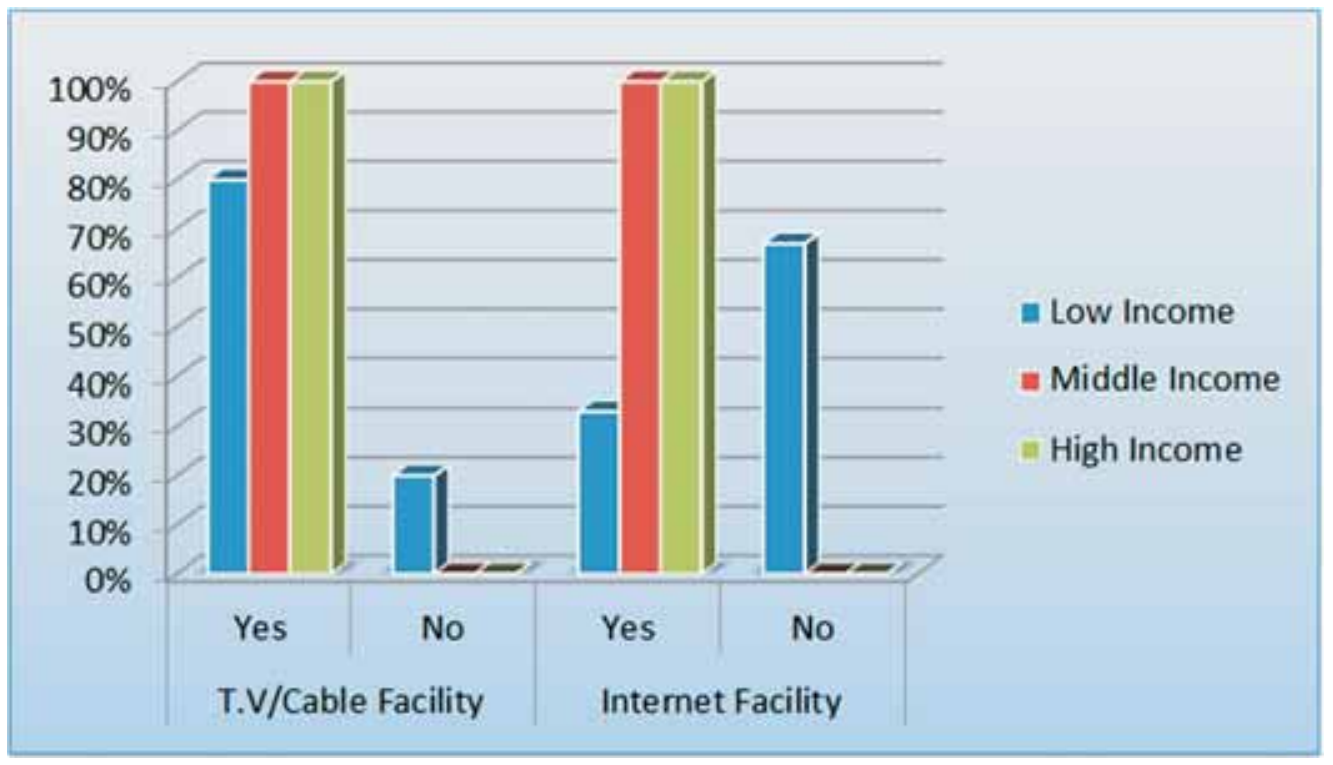

Figure 2: People having T.V/ cable and internet facility

Table 3: Free Time on Working Day

\begin{tabular}{|lllllll|}
\hline & $\begin{array}{l}\text { Less than } \\
\mathbf{1} \text { hour }\end{array}$ & $\begin{array}{l}\text { 1 hour or less } \\
\text { than } \mathbf{2} \text { hour }\end{array}$ & $\begin{array}{l}\mathbf{2} \text { hour or less } \\
\text { than } \mathbf{3} \text { hour }\end{array}$ & $\begin{array}{l}\text { More than } \\
\mathbf{3} \text { hours }\end{array}$ & N/A & Total \\
Low Income & $13.30 \%$ & $36.70 \%$ & $23.30 \%$ & $10 \%$ & $16.70 \%$ & $100 \%$ \\
Middle Income & $63.30 \%$ & $23.30 \%$ & $6.70 \%$ & $6.70 \%$ & $0 \%$ & $100 \%$ \\
High Income & $10 \%$ & $20.00 \%$ & $36.67 \%$ & $33.33 \%$ & $0 \%$ & $100 \%$ \\
\hline
\end{tabular}

internet facility respectively which is because of low affordability. Use of internet has become an emerging trend in high and middle income houses over the past ten years. This is the root cause of passive recreation in Pakistani society.

\section{Free Time on Working Days}

One cannot enjoy any type of recreational activity unless he/she has spare time for it. It has been found that most households have less than three hours as free time daily (Table-3). Most of the low and high income households surveyed had more than three hours free time for recreation and family. While, middle income classes were found to be the busiest among the three income groups with less than two hours as free time.

\section{Time Spent on Watching TV and Net Surfing}

Once free time available to people had been calculated, the next step was to find the time spend on different recreational activities. High income people spent their maximum time watching television and net surfing. Middle income households spend less time on such activities. Mostly low income households don't have internet facility that is why $20 \%$ don't fall under this category. Middle income households have been found more responsive towards spending less time watching television and net surfing (Table-4).

\section{Analysis and Discussion}

Overall, on the basis of collected data and its analysis, it is seen that in the Metropolitan city of Lahore, people in different income groups have divergent attitudes towards passive recreation. It is proven that this shift towards passive recreation is the result of lack of playgrounds both in societies and schools and high impact of technology, as people are more attracted towards passive recreation and because of academic pressures and security issues (Frumkin et al, 2004). More specifically, different reasons are found for increasing trend towards passive recreation in different income societies (McInode et al, 2005). In low income societies the most 
Table 4: Time Spent on Watching TV and Internet Surfing

\begin{tabular}{|llllll|}
\hline & $\begin{array}{l}\text { Less than } \\
\text { 1 hour }\end{array}$ & $\begin{array}{l}\text { 1 hour or less } \\
\text { than } \mathbf{2} \text { hour }\end{array}$ & $\begin{array}{l}\text { 2 hour or less } \\
\text { than 3 hour }\end{array}$ & $\begin{array}{l}\text { More than } \\
\mathbf{3} \text { hours }\end{array}$ & Total \\
Low Income & $3.30 \%$ & $20 \%$ & $33.30 \%$ & $43.30 \%$ & $100 \%$ \\
Middle Income & $6.70 \%$ & $40 \%$ & $26.70 \%$ & $26.70 \%$ & $100 \%$ \\
High Income & $0 \%$ & $10 \%$ & $46.70 \%$ & $43.30 \%$ & $100 \%$ \\
\hline
\end{tabular}

apparent cause towards the increasing trend of passive recreation is the lack of playgrounds in their vicinity, as the people do not find any playgrounds or proper place to perform active recreation therefore these people have less intentions towards active recreation. The other reason that low income groups do not engage in active recreation is their long working hours as they are unable to find enough time to perform active recreation after a whole day of hectic work. In such a scenario people are attracted towards passive recreation by spending time with their family members and watching T.V, computer or video games in their house, street or shops. This impact of technology however, is relatively less on low income societies than on middle and high income areas.

In middle income societies, there is a lack of playgrounds or sports complexes, hence they are unable to perform active recreation frequently. These people also cite security as a reason, since they have to go to faraway places for recreation thus road accidents are also citied as reason for lack of engagement in active recreation. On the other hand they are more attracted towards use of technology like internet surfing, online games, smart phones sharing chatting and outdoor shopping, hoteling, etc. These types of recreation activities have a great impact on their lives as all these activities fall under the category of passive recreation.

In high income societies people have access to playgrounds but not at large, and although planning authorities have started providing sports complexes but due to security reasons and high impact of technology people are more attracted towards passive recreation. These people have more interest towards hoteling, nature exposure, picnic, gaming and net surfing.

In response to the question asked about the number of families visiting the park or playground it was found that about $40 \%$ in all income societies, answered in the affirmative, but the ratio of females in response to this question was relatively low, particularly in age groups of upto 25 years. $90 \%$ of females do not use parks as it is not culturally accepted. There is very low percentage of people engaged in active recreation and the reason behind this is the unavailability of proper arrangements for active recreation. Consequently, a large number of people who are keen to engage in active recreation use the streets or personal property for this purpose.

It has been found that in middle and low income societies, children studying in private or government schools have no playgrounds thus their engagement in active recreation is minimal as they do not also have adequate areas in their localities for active recreation.

Planning authorities have failed to provide adequate and enough play areas or sports complexes within neighbourhoods so that people can engage in active recreation. Furthermore, management of local playgrounds is not providing any special facilities or clubs that promote active recreation in an effective manner. Almost $100 \%$ of the respondents desired to have grounds or play areas where they could perform active recreation. Recently it has been witnessed that the local government has started to provide active recreational facilities in parks, but it will take time and promotional measures to implement this successfully and to keep a balance between active and passive recreational activities.

\section{CONCLUSIONS}

It is concluded that in Lahore people are more focused towards passive recreation as compared to active recreation. The reason for such a scenario is the lack of play area facilities for people and the easy accessibility to passive recreation like availability of technology. Further, where open spaces are available people are not using them due to security reasons. Some people who are keen on engaging in active recreational activities, perform them on personal 
property or on the streets. Moreover, most of the schools have no playgrounds for children, which is an alarming situation. Therefore, it is recommended that planning authorities should provide play areas in each locality, make compulsory provision of playgrounds in new housing schemes and schools. The situation is worse in old developed areas where availability of empty plots is an issue because of high density.

\section{REFERENCES}

Bryman, A., 2008, Social research methods, Oxford University Press, Oxford.

Carmona, M., Heath, T., et al., 2010, Public places: Urban spaces, Routledge, Oxford.

Dong, E. and Chick, G., 2012, 'Leisure constraints in six Chinese cities', Leisure Science: An Inter Disciplinary Journal, 34(5), 417-435.

Douglas, F., 2009, Sustainable urbanism: Urban design with nature, Wiley, New York.

Frank, L.D., Engelke, P. et al., 2003, Health and community design. The impact of the built environment on physical activity, Island Press, Washington.

Friedmann, J., 2007, 'Reflections on Place and Place: making in the Cities of China', International Journal of Urban and Regional Research, 31(2), 257-279.

Frumkin, H., Frank, L. and Jackson, R., 2004, Urban Sprawl and Public Health: Designing, Planning, and Building for Healthy Communities, Island Press, Washington.

Haughey, R. M., 2005, Higher-density development: Myth and fact, The Urban Land Institute, Washington.

Howe, A.D., 2007, Research methods for leisure, recreation and tourism, San Francisco state University, San Francisco.

Hui-fen, Z., Zhen-shan, L. et al., 2012, 'Time use patterns between maintenance, subsistence and leisure activities: A case study in China', Social Indicators Research, 105(1), 121-136.

Katcher, A. and Beck, A., 1987, 'Health and caring for living things', Anthrozoos, (1), 175-183.

Kuo, F. and Sullivan, W., 2001, 'Aggression and violence in the inner city: Effects of environment via mental fatigue', Environment and Behavior, 33(4), 543-571.

Maller, C., Townsend, M. et al., 2002, Healthy parks healthy people. The health benefits of contact with nature in a park context, Deakin University, Melbourne.

McIndoe, G. Chapman, R. et al., 2005, The value of urban design. The economic, environmental and social benefits of urban design, Ministry for the Environment, Wellington.

McLean, D. and Hurd, A., 2011, Recreation and leisure in modern society, Jones and Bartlett, Burlington.

PIDE, 2011, Estimating the middle class in Pakistan, Pakistan Institute of Development Economics Working Paper, Islamabad.

Saelens, B., Sallis, J. et al., 2003, 'Environmental correlates of walking and cycling: Findings from the transportation, urban design, and planning literatures', Annals of Behavior Medicine, 25, 80-91.

Saelens, B., Sallis, J. et al., 2003a, 'Neighborhood based differences in physical activity: An environment scale evaluation', American Journal of Public Health, 93, 1552-1558.

Sutton, L., 2008, 'The state of play: Disadvantage, play and children's well-being', Social Policy and Society, 7(4), 537549.

Williams, S., 2000, Outdoor recreation and the urban environment, Routledge, London.

Zhang, L., 2010, In Search of paradise: Middle class living in a Chinese metropolis, Cornell University Press, Ithaca. 